\title{
The mucopolysaccharidoses: a success of molecular medicine - CORRIGENDUM
}

\section{Lorne A. Clarke}

doi: 10.1017/S1462399408000550, Published by Cambridge University Press, 18 January 2008

Some enzyme names given in Table 1 of the review by L.A. Clarke (Ref. 1) were incorrect. The corrected table is presented here.

\section{Table 1. Classification of the MPSs}

\begin{tabular}{|c|c|c|c|c|}
\hline Name & OMIM & Enzyme & Gene loc. & GAG substrates \\
\hline $\begin{array}{l}\text { MPS I } \\
\text { (Hurler, Hurler-Scheie, } \\
\text { and Scheie syndromes) }\end{array}$ & $\begin{array}{l}607014 \\
607015 \\
607016\end{array}$ & $\alpha$-L-iduronidase & $4 p 16.3$ & $\begin{array}{l}\text { Dermatan sulphate } \\
\text { Heparan sulphate }\end{array}$ \\
\hline $\begin{array}{l}\text { MPS II } \\
\text { (Hunter syndrome) }\end{array}$ & 309900 & Iduronate-2-sulphatase & Xq28 & $\begin{array}{l}\text { Dermatan sulphate } \\
\text { Heparan sulphate }\end{array}$ \\
\hline $\begin{array}{l}\text { MPS III A } \\
\text { (Sanfilippo syndrome) }\end{array}$ & 252900 & Glucosamine $N$-sulphatase & $17 q 25.3$ & Heparan sulphate \\
\hline $\begin{array}{l}\text { MPS III B } \\
\text { (Sanfilippo syndrome) }\end{array}$ & 252920 & $\alpha-N$-acetylglucosaminidase & $17 q 21$ & Heparan sulphate \\
\hline $\begin{array}{l}\text { MPS III C } \\
\text { (Sanfilippo syndrome) }\end{array}$ & 252930 & $\begin{array}{l}\text { Acetyl CoA: } \alpha \text {-glucosamine } \\
N \text {-acetyl transferase }\end{array}$ & $8 p 11.1$ & Heparan sulphate \\
\hline $\begin{array}{l}\text { MPS III D } \\
\text { (Sanfilippo syndrome) }\end{array}$ & 252940 & $\begin{array}{l}N \text {-acetylglucosamine-6- } \\
\text { sulphatase }\end{array}$ & $12 q 14$ & Heparan sulphate \\
\hline $\begin{array}{l}\text { MPS IV A } \\
\text { (Morquio syndrome A) }\end{array}$ & 253000 & $\begin{array}{l}\text { Galactosamine-6- } \\
\text { sulphatase }\end{array}$ & $16 q 24.3$ & Keratan sulphate \\
\hline $\begin{array}{l}\text { MPS IV B } \\
\text { (Morquio syndrome B) }\end{array}$ & 253010 & $\beta$-D-galactosidase & $3 p 21.33$ & Keratan sulphate \\
\hline $\begin{array}{l}\text { MPS VI } \\
\text { (Maroteaux-Lamy } \\
\text { syndrome) }\end{array}$ & 253200 & $\begin{array}{l}N \text {-acetylgalactosamine-4- } \\
\text { sulphatase }\end{array}$ & $15 q 12$ & Dermatan sulphate \\
\hline $\begin{array}{l}\text { MPS VII } \\
\text { (Sly syndrome) }\end{array}$ & 253220 & $\beta$-glucuronidase & $7 q 21.11$ & $\begin{array}{l}\text { Dermatan sulphate } \\
\text { Heparan sulphate }\end{array}$ \\
\hline $\begin{array}{l}\text { MPS IX } \\
\text { (Natowicz disease) }\end{array}$ & 610492 & Hyaluronidase & $3 p 21.1$ & Hyaluronan \\
\hline
\end{tabular}

\section{Reference}

1 Clarke, L.A. (2008) The mucopolysaccharidoses: a success of molecular medicine. Expert Rev. Mol. Med. 10, e1 